\title{
Implementation and Performance Evaluation of Three Routing Protocols for Mobile Ad Hoc Network Using Network Simulator
}

\author{
Suhaila A. Dabibbi and Shawkat K. Guirguis
}

\begin{abstract}
Mobile ad hoc network (MANET) is a self-configuring infrastructure less network of mobile nodes connected by wireless links - the union of which form a random topology. There are several IP routing protocols, with competing features, developed for wireless ad hoc networks. These protocols have varying qualities for different wireless routing aspects. It is due to this reason that choice of a correct routing protocol is critical. In this paper, two main questions are addressed. The first is 'Which routing protocol provides a better performance in mobile ad hoc Networks?' This question addresses the overall performance of each routing protocol investigated in this paper. The second question addresses the factors that influence the performance of these routing protocols.

In this paper, Three protocols ad hoc on-Demand Distance Vector Routing (AODV), Dynamic Source Routing (DSR), and Destination-Sequenced Distance Vector (DSDV) were compared in terms of Average End-to-End Delay, Average Throughput, Packet Delivery Ratio, Total Dropped Packets, and Normalized Routing Load in different environment; varying number of nodes and simulation Time. All simulation result implement at network simulator-2 (NS-2.35).
\end{abstract}

Index Terms-Ad hoc on-demand distance vector routing (AODV), destination-sequenced distance vector (DSDV), dynamic source routing (DSR), and mobile ad hoc network (MANET), and network simulator 2 (NS2.35).

\section{INTRODUCTION}

Mobile ad hoc Network (MANET) [1]-[3] as in Fig. 1 is a group of wireless node, which rapidly moves, changes and forms a network without need of centralized controlling entity . The entire nodes in MANET intercommunicate with other node which stays in its relative frequency range. Each node in MANET works as router, so each node forward packet to neighbor node until packet it reaches to destination. There are many routing protocols [2]-[5] as DSR, AODV, DSDV, Temporary Ordered Routing Protocol (TORA), and Optimized Link State Routing (OLSR) each having its own working mechanism.

In this paper we presented performance comparability with AODV, DSR, and DSDV protocols based on metrics such as Average End-to-End Delay, Average Throughput, packet

Manuscript received February 14, 2014; revised April 18, 2014.

S. A. Dabibbi was with the Computer Science, Elmergib, University, Libya. He is now with the Institute of Graduate Studies \& Research (IGSR), Alexandria University, Egypt (e-mail: Dabibi_s@yahoo.com).

S. K. Guirguis is with the Computer Science and Informatics, Department of Information Technology, Institute of Graduate Studies \& Research (IGSR), Alexandria University, Egypt (e-mail: shawkat_g@yahoo.com). delivery ratio, Total Dropped Packets, and Normalized Routing Load (routing overhead) by using NS2 Simulator.

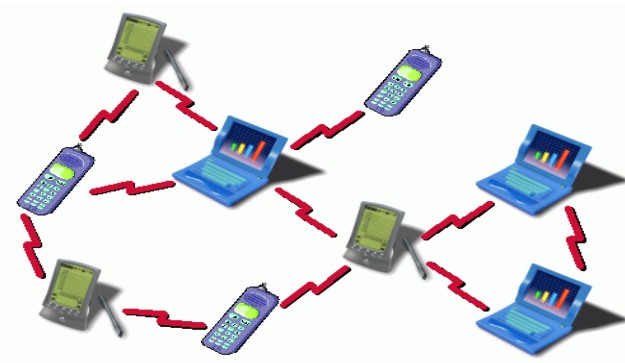

Fig. 1. Mobile ad-hoc network.

Advantages and Applications of MANET [6]

- Provide access to information and services.

- Regardless of geographic position.

- These networks can be set up at any place and time.

- Some of the applications of MANETs are Military or police exercises.

- Disaster relief operations.

- Mine cite operations.

- Urgent Business meeting

\section{ROUTING PROTOCOLS OF MANET}

A routing protocol [1], [2], [7] is used to transmit a packet to a destination via number of nodes and numerous routing protocols have been proposed for such kind of ad-hoc networks. Classification of MANET Routing can be broadly classified into three types As in Fig. 2.

\section{A. Proactive Protocols}

In networks utilizing a proactive routing protocol, each node in a network maintains one or more routing tables which are updated regularly. Each node sends a broadcast message to the entire network if there is a change in the network topology. However, it incurs additional overhead cost due to maintaining up-to-date information and as a result; throughput of the network may be affected but it provides the actual information to the availability of the network. Distance vector (DV) protocol, Destination Sequenced Distance Vector (DSDV) protocol, Wireless Routing protocol Fisheye State Routing (FSR) protocol, and (OLSR) are the examples of Proactive protocols.

\section{B. Reactive Protocols}

Unlike proactive routing protocols, each node in a network discovers or maintains a route based on-demand. It floods a control message by global broadcast during discovering a 
route and when route is discovered then bandwidth is used for data transmission. The main advantage is that this protocol needs less touting information but the disadvantages are that it produces huge control packets due to route discovery during topology changes which occurs frequently in MANETs and it incurs higher latency. The examples of this type of protocol are Dynamic Source Routing (DSR), ad-hoc On Demand Routing (AODV) and Associativity Based Routing (TORA) protocols.

\section{Hybrid Protocols}

It is a combination of proactive and reactive protocols taking the best features from both worlds as Zone Routing Protocol

(ZRP).

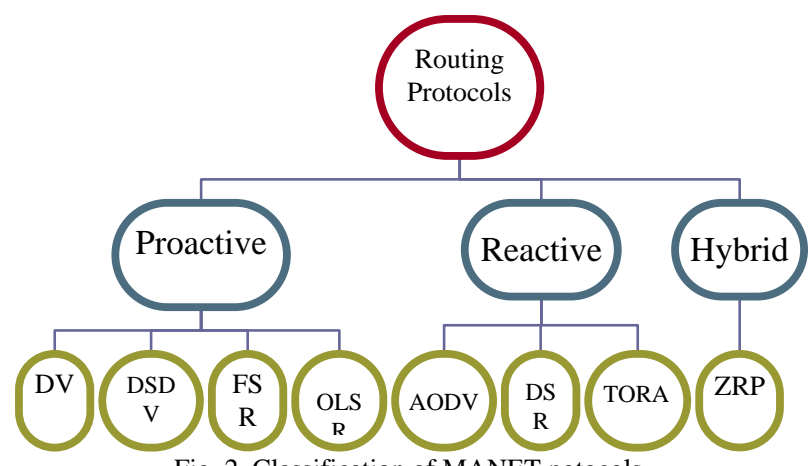

Fig. 2. Classification of MANET potocols.

In this paper, three protocols are used only DSR, AODV, DSDV protocols. [1] The narrative of these protocols is given below

\section{1) Ad hoc on-demand distance vector routing ( $A O D V)$ protocol}

The ad hoc on-demand distance vector routing (AODV) protocol [3], [8], [9] is a reactive unicast routing protocol for mobile ad hoc networks. As a reactive routing protocol, AODV only needs to maintain the routing information about the active paths. In AODV, routing information is maintained in routing tables at nodes. Every mobile node keeps a next-hop routing table, which contains the destinations to which it currently has a route. A routing table entry expires if it has not been used or reactivated for a pre-specified expiration time.

\section{2) The dynamic source routing (DSR) protocol}

The Dynamic Source Routing (DSR) is a reactive unicast routing protocol [3], [8], [10] that utilizes source routing algorithm. In source routing algorithm, each data packet contains complete routing information to reach its dissemination. Additionally, in DSR each node uses caching technology to maintain route information that it has learnt. There are two major phases in DSR, the route discovery phase and the route maintenance phase. When a source node wants to send a packet, it firstly consults its route cache. If the required route is available, the source node includes the routing information inside the data packet before sending it.

DSR main advantages is the fact that it is a reactive (on-demand) protocol hence it does not flood the network with routing updates even when the link is not in use. A route is only determined when needed. There is no need to discover routes to all the nodes in the network. And the cached information in the intermediate nodes is used to reduce routing overhead.

The disadvantage is that failed routes are not repaired locally. The cached information in the nodes may result in building inconsistent routes during reconstruction. There is high setup latency compared to the table-driven protocols. DSR is well suited for static and low-mobility networks. High mobility reduces its performance

\section{3) The destination sequence distance vector (DSDV) routing protocol}

The Destination Sequence Distance Vector (DSDV) [3] is a proactive unicast mobile ad hoc network routing protocol. Like WRP, DSDV is also based on the traditional Bellman-Ford algorithm. However, their mechanisms to improve routing performance in mobile ad hoc networks are quite different. In routing tables of DSDV, an entry stores the next hop towards a destination, the cost metric for the routing path to the destination and a destination sequence number that is created by the destination. Sequence numbers are used in DSDV to distinguish stale routes from fresh ones and avoid formation of route loops. The route updates of DSDV can be either time-driven or event-driven. Every node periodically transmits updates including its routing information to its immediate neighbors.

\section{PERFORMANCE METRIC}

Some following important performance metrics can be evaluated:

1) Average End-to-End Delay - It is the average time that packets take to traverse the network [1], [4]. This is the time from the generation of the packet by the sender up to their reception at the destination's application layer and is expressed in seconds. It therefore includes all the delays in the network such as buffer queues, transmission time and delays induced by routing activities and MAC control exchanges.

2) Average Throughput - It is the ratio of the total amount of data that reaches a receiver from a sender to the time it takes for the receiver to get the last packet is referred to as throughput [1]. It is expressed in bits per second or packets per second. Factors that affect throughput in MANETs include frequent topology changes, unreliable communication, limited bandwidth and limited energy. A high throughput network is desirable.

3) Packet Delivery Ratio $(P D R)$ - It is the ratio between the number of packets delivered to the receiver and the number of packets sent by the source [1], [4]. It characterises both the correctness and efficiency of ad hoc routing protocols. It represents the maximum throughput that the network can achieve. A high packet delivery ratio is desired in a network.

4) Total Packet Dropped - It is the failure of one or more transmitted packets to arrive at their destination [4].

5) Normalized Routing Load (or Normalized Routing Overhead) - It is defined as the total number of routing packet transmitted per data packet [1], [4]. It is calculated by dividing the total number of routing packets sent (includes forwarded routing packets as well) by the total number of data packets received. 


\section{Simulation Model}

Network Simulator NS-2(NS-2.35) is a discrete event simulator mostly used for research in networking.NS2 used for both wire and wireless network protocol and also with their function. NS-2 provides substantial support for simulation of TCP, routing and multicast protocols in wired and wireless (local and satellite).

A comparison and performance evaluation performed by NS2 for three routing protocols AODV, DSR, and DSDV. Simulation experiment result based on Average End-to-End Delay, Average Throughput, packet delivery ratio, Total Dropped Packets, and Normalized Routing Load (routing overhead) with the following parameter (see Table I).

TABLE I: SIMULATION PARAMETER

\begin{tabular}{cc}
\hline \hline Parameter & Value \\
\hline Area & $1500 \times 1500$ \\
Simulation Time & $100,200,300,400,500$ \\
MAC layer protocol & IEEE 802.11 \\
Routing protocol & AODV , DSR,and DSDV \\
Number of nodes & 25,50,and 75 respectively \\
Antenna Model & Omni-directional \\
Channel type & Channel/Wireless channel \\
Link Layer Type & LL \\
Traffic type & 50 \\
Maximum Packet & Propagation/TwoRayGround \\
Radio-propagation Model & Phy/WirelessPhy \\
Network interface Type & Queue/DropTail/PriQueue \\
Interface Queue Type & Two Ray Model \\
Path Loss Model &
\end{tabular}

\section{Simulation RESUltK AND ANALYSIS}

The performance of protocol compare with respect to: Average End-to-End Delay measurement (see Table II, Table III, Table IV), then the number of nodes connected in a network as varying with simulation time shown in Fig. 3 Fig. 5, through which the comparison graphs of AODV, DSDV and DSR is obtained.

\section{TABLE II: AVERAGE END-TO-END RESULTS FOR 25 NODE}

\begin{tabular}{lrrrrr}
\hline \hline $\begin{array}{l}\text { Average } \\
\text { End-to-End } \\
\text { Delay [ms] }\end{array}$ & 100 & 200 & 300 & 400 & 500 \\
\hline & & & & & \\
DSR & 358.671 & 366.911 & 371.096 & 365.233 & 383.872 \\
DSDV & 271.504 & 258.714 & 269.162 & 259.692 & 256.114 \\
AODV & 221.014 & 208.576 & 217.43 & 255.991 & 275.393 \\
\hline \hline
\end{tabular}

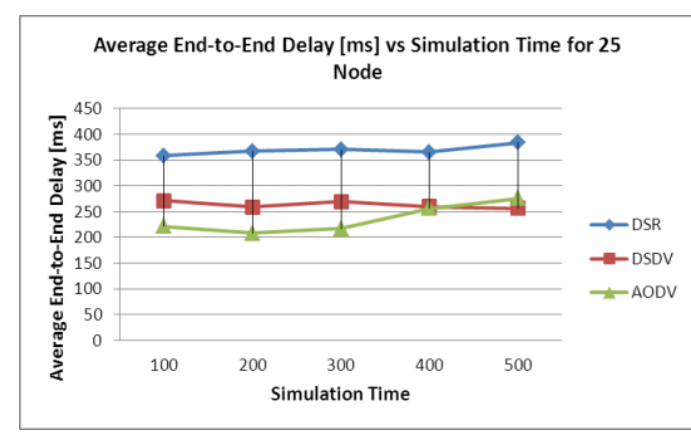

Fig. 3. Average end-to-end delay for 25 node.
TABLE III: AVERAGE END-TO-END RESULTS FOR 50 NODE

\begin{tabular}{cccccc}
\hline \hline $\begin{array}{c}\text { Average } \\
\text { End-to-End } \\
\text { Delay [ms] }\end{array}$ & 100 & 200 & 300 & 400 & 500 \\
\hline DSR & 564.782 & 537.194 & 595.049 & 662.369 & 596.197 \\
DSDV & 217.956 & 286.367 & 278.061 & 290.976 & 314.61 \\
AODV & 306.83 & 410.399 & 409.35 & 390.41 & 395.575 \\
\hline \hline
\end{tabular}

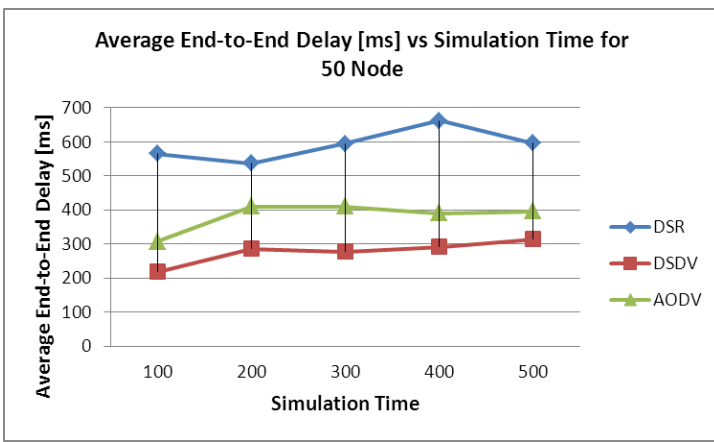

Fig. 4. Average end-to-end delay for 50 node.

TABLE IV: AVERAGE END-TO-END RESULTS FOR 75 NODE

\begin{tabular}{cccccc}
\hline \hline $\begin{array}{c}\text { Average } \\
\text { End-to-End } \\
\text { Delay [ms] }\end{array}$ & 100 & 200 & 300 & 400 & 500 \\
\hline DSR & 464.53 & 570.227 & 663.51 & 702.999 & 739.753 \\
DSDV & 255.745 & 367.224 & 422.568 & 434.123 & 454.731 \\
AODV & 589.066 & 589.809 & 593.773 & 542.471 & 528.266 \\
\hline \hline
\end{tabular}

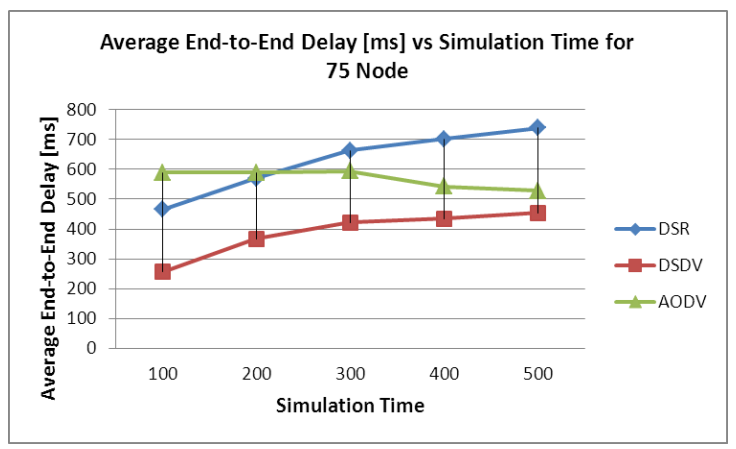

Fig. 5. Average end-to-end delay for 75 node.

The measurement values of average End-to-End delay (see Table V - Table VII) represent that reliability of routing protocol in the network. The comparison of above Fig. 3 for 25 node shows that when the speed of node increases with simulation time, average delay of AODV decreases while in DSDV and DSR, average delay increases with the increase in node speed. It means AODV take less time to deliver the data from source to destination as node speed increases in AODV. but as the traffic will increase with the number of nodes such as 50 and 75 nodes in the network which is shown in Fig. 4, Fig. 5 respectively, average End-to-End delay value of DSDV is best in greater number of nodes with long simulation time.

Average Throughput measurement, then the number of nodes connected in a network as varying with simulation time shown in Fig. 6-Fig. 8, through which the comparison graphs of AODV, DSDV and DSR is obtained. 
TABLE V: AVERAGE THROUGHPUT RESULTS FOR 25 NODE

\begin{tabular}{lrrrrr}
\hline \hline $\begin{array}{l}\text { Average } \\
\begin{array}{l}\text { Throughput } \\
{[\mathrm{kbps}]}\end{array}\end{array}$ & 100 & 200 & 300 & 400 & 500 \\
\hline DSR & 586.5 & 581.54 & 588.5 & 591.44 & 593.32 \\
DSDV & 621.62 & 618.5 & 615.66 & 607.22 & 604.98 \\
& 625.94 & 522.95 & 489.7 & 476.35 & 467.57 \\
\hline
\end{tabular}

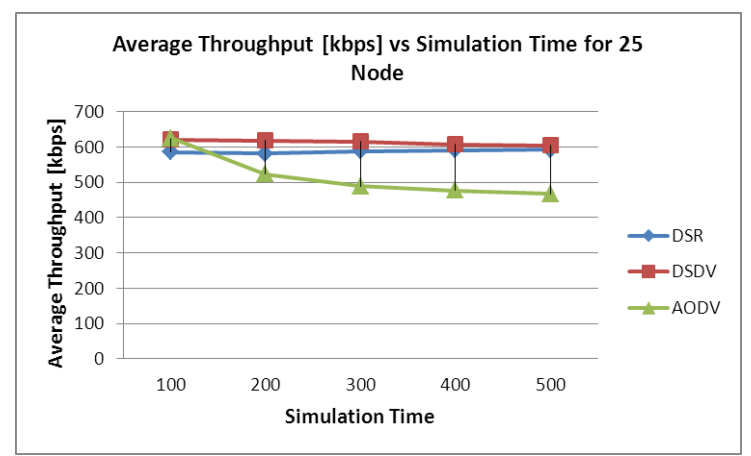

Fig. 6. Average throughput [kbps] for 25 node.

TABLE VI: AVERAGE THROUGHPUT RESULTS FOR 50 NODE

\begin{tabular}{lccccc}
\hline \hline $\begin{array}{l}\text { Average } \\
\text { Throughput } \\
{[\mathrm{kbps}]}\end{array}$ & 100 & 200 & 300 & 400 & 500 \\
\hline DSR & 457.32 & 453.03 & 446.49 & 440.41 & 441.41 \\
& & & & & \\
DSDV & 473.78 & 446.98 & 434.56 & 427.9 & 428.37 \\
AODV & 435.31 & 444.03 & 453.49 & 441.22 & 431.93 \\
\hline \hline
\end{tabular}

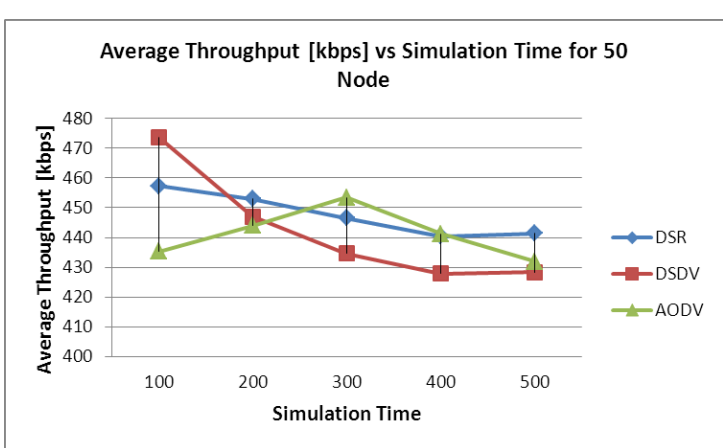

Fig. 7. Average throughput [kbps] for 50 node.

TABLE VII: AVERAGE THROUGHPUT RESULTS FOR 75 NODE

\begin{tabular}{lrrrrr}
\hline \hline $\begin{array}{l}\text { Average } \\
\text { Throughput } \\
{[\mathrm{kbps}]}\end{array}$ & 100 & 200 & 300 & 400 & 500 \\
\hline DSR & 531.92 & 532.99 & 530.03 & 525.19 & 525.39 \\
DSDV & 531.87 & 525.31 & 500.18 & 454.82 & 413.8 \\
AODV & 438.57 & 466.46 & 486.11 & 502.91 & 510.27 \\
\hline \hline
\end{tabular}

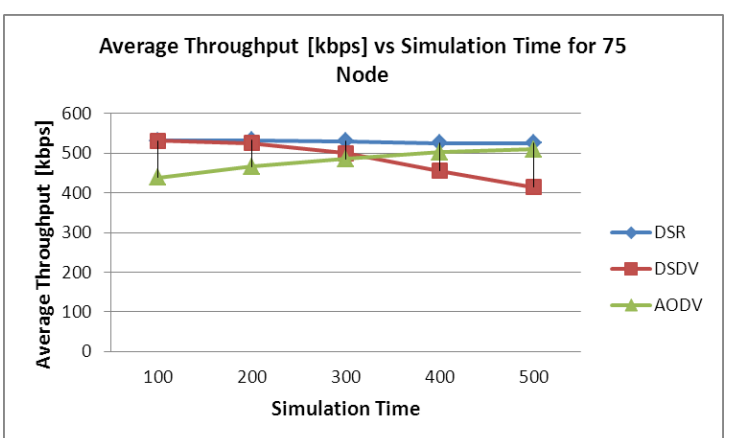

Fig. 8. Average throughput [kbps] for 75 node.
Based on the simulation results, the throughput value of AODV for 25 node shown in Fig. 6 shows better performance with respect to throughput among these three protocols. For 50 node shown in Fig. 7 show that before simulation time 200 AODV is the best after 200 became DSDV the best as DSDV decreases and AODV increases. For 75 node shown in Fig. 8 show that before simulation time $300 \mathrm{AODV}$ is the best after 300 became DSDV the best.

Packet delivery ratio measurement(see Table VIII-Table $\mathrm{X})$, then the number of nodes connected in a network as varying with simulation time shown in Fig. 9-Fig. 11, through which the comparison graphs of AODV, DSDV and DSR is obtained

\begin{tabular}{lccccc}
\multicolumn{6}{c}{ TABLE VIII: PACKET DELIVERY RATIO RESULTS FOR 25 NODE } \\
\hline $\begin{array}{l}\text { Packet } \\
\begin{array}{l}\text { Delivery } \\
\text { Ratio }\end{array}\end{array}$ & 100 & 200 & 300 & 400 & 500 \\
\hline DSR & 97.9015 & 98.7278 & 98.9627 & 99.2154 & 98.898 \\
DSDV & 96.5644 & 97.3963 & 97.6412 & 97.6102 & 97.6276 \\
AODV & 97.307 & 98.0834 & 98.5772 & 98.8475 & 98.9892 \\
\hline
\end{tabular}

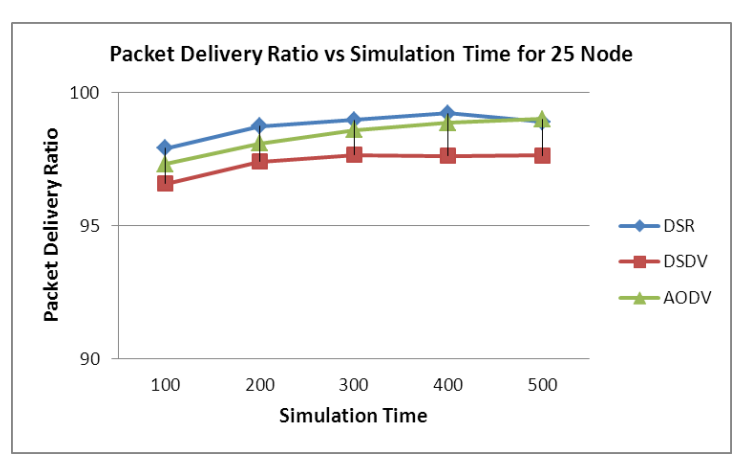

Fig. 9. Packet delivery ratio for 25 node.

TABLE IX: PACKet Delivery RATIO Results For 50 NODE

\begin{tabular}{lrrrrr}
\hline \hline $\begin{array}{l}\text { Packet } \\
\text { Delivery } \\
\text { Ratio }\end{array}$ & 100 & 200 & 300 & 400 & 500 \\
\hline DSR & 90.8489 & 93.2928 & 92.5275 & 93.5183 & 93.7623 \\
& & & & & \\
DSDV & 89.3565 & 91.3182 & 90.4497 & 89.1703 & 87.8783 \\
AODV & 96.1097 & 96.8815 & 97.4659 & 97.5638 & 97.6697 \\
\hline \hline
\end{tabular}

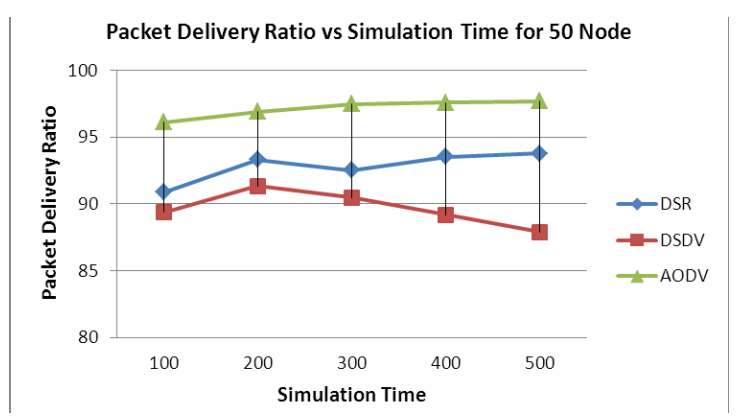

Fig. 10. Packet delivery ratio for 50 node.

TABLE X: PACKet DeLIVERY RATIO RESUltS FOR 75 NODE

\begin{tabular}{lrrrrr}
\hline \hline $\begin{array}{l}\text { Packet } \\
\begin{array}{l}\text { Delivery } \\
\text { Ratio }\end{array}\end{array}$ & 100 & 200 & 300 & 400 & 500 \\
\hline DSR & 91.2696 & 92.8764 & 93.7368 & 93.9894 & 93.9626 \\
DSDV & 87.3992 & 89.0951 & 87.3239 & 79.3109 & 72.3122 \\
AODV & 94.5839 & 95.543 & 95.8471 & 96.1817 & 96.414 \\
\hline \hline
\end{tabular}




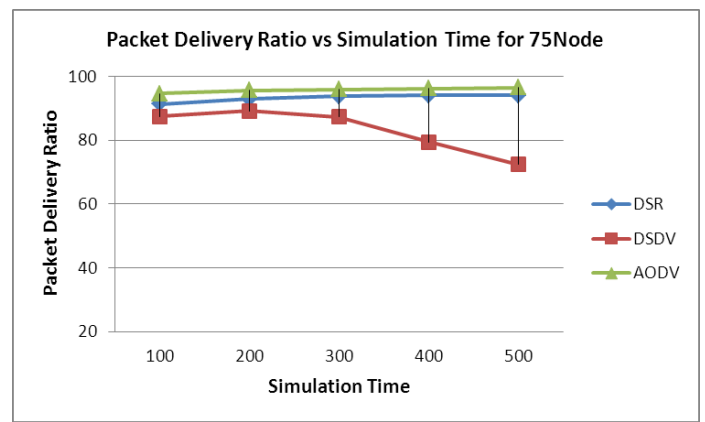

Fig. 11. Packet delivery ratio for 75 node.

For 25 node shown in Fig. 9, depict that the Packet Delivery Ratio value of DSR is the best. The Packet Delivery Ratio value of AODV and DSR is higher than DSDV at present of 50, and 75 node shown in Fig. 10, Fig. 11 in the network, the Packet Delivery Ratio value of DSDV is worse in greater number of nodes with long simulation time. From the above study, in view of packet delivery ratio, reliability of AODV and DSR protocols is greater than DSDV protocol.

Total Dropped Packets measurement (see Table XI-Table $\mathrm{XIII)}$, then the number of nodes connected in a network as varying with simulation time shown in Fig. 12-Fig. 14, through which the comparison graphs of AODV, DSDV and DSR is obtained.

\begin{tabular}{lrrrrr}
\multicolumn{6}{c}{ TABLE XI: TOTAL DROPPED PACKETS RESULTS FOR 25 NODE } \\
\hline \hline Total & 100 & 200 & 300 & 400 & 500 \\
Dropped & & & & & \\
Packets & & & & & \\
\hline DSR & 57 & 83 & 113 & 103 & 149 \\
DSDV & 64 & 118 & 169 & 264 & 282 \\
AODV & 303 & 325 & 350 & 354 & 364 \\
\hline \hline
\end{tabular}

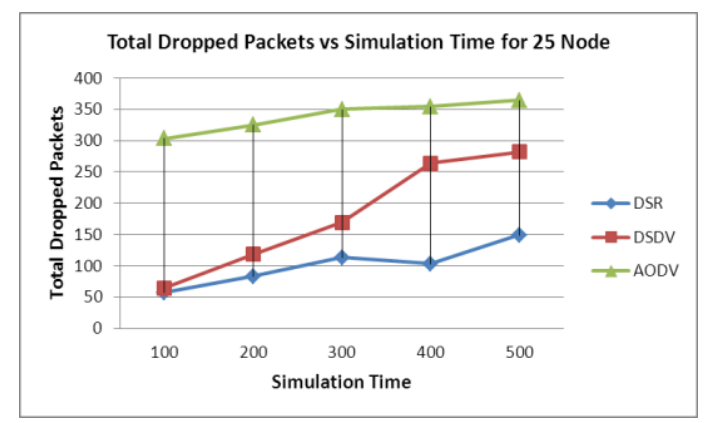

Fig. 12. Total dropped packets for 25 node.

TABLE XII: TOTAL DROPPED PACKETS RESUlTS FOR 50 NODE

\begin{tabular}{rccccc}
\hline $\begin{array}{r}\text { Total } \\
\text { Dropped } \\
\text { Packets }\end{array}$ & 100 & 200 & 300 & 400 & 500 \\
\hline DSR & 109 & 161 & 247 & 310 & 334 \\
DSDV & 152 & 290 & 399 & 519 & 684 \\
AODV & 153 & 212 & 347 & 429 & 478 \\
\hline \hline
\end{tabular}

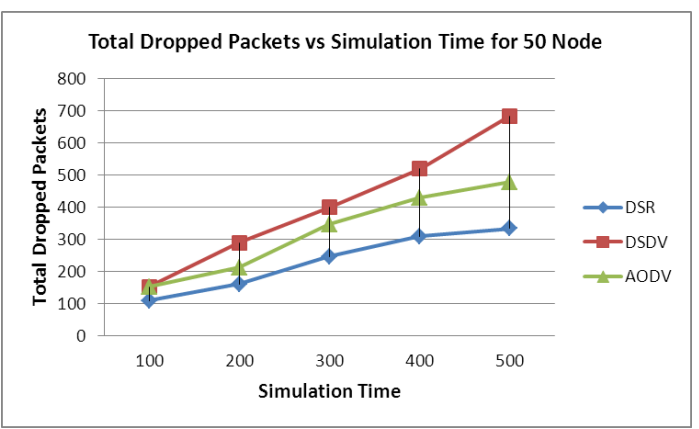

Fig. 13. Total dropped packets for 50 node.
TABLE XIII: TOTAL DROPPED PACKETS RESULTS FOR 75 NODE

\begin{tabular}{rccccc}
\multicolumn{5}{c}{ TABLE XIII: TOTAL DROPPED PACKETS RESULTS FOR 75 NODE } \\
\hline $\begin{array}{r}\text { Total } \\
\begin{array}{r}\text { Dropped } \\
\text { Packets }\end{array}\end{array}$ & 100 & 200 & 300 & 400 & 500 \\
\hline DSR & 101 & 213 & 264 & 301 & 410 \\
& & & & & \\
DSDV & 168 & 353 & 504 & 667 & 852 \\
AODV & 231 & 495 & 698 & 947 & 1107 \\
\hline \hline
\end{tabular}

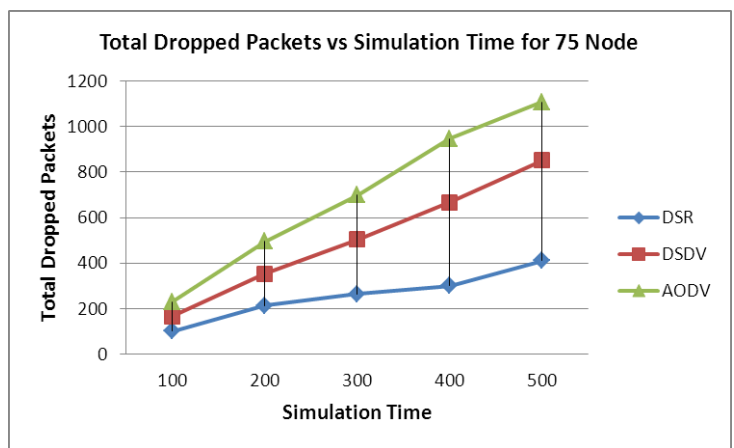

Fig. 14. Total dropped packets for 75 node

The Total Dropped Packets value of DSR is the best shown in Fig. 12-Fig. 14 at present of 25, 50, and 75 node in the network, it give less Dropped Packets. The Total Dropped Packets value of AODV and DSDV is worse in greater number of nodes with long simulation time. From the above study, in view of Total Dropped Packets, DSR protocols is the best protocol.

Normalized Routing Load (routing overhead) measurement( see Table XIV-Table XVI), then the number of nodes connected in a network as varying with simulation time shown in Fig. 15,16,17, through which the comparison graphs of AODV, DSDV and DSR is obtained.

\begin{tabular}{rccccc}
\multicolumn{6}{c}{ TABLE XIV: NORMALIZED ROUTING LOAD RESULTS FOR 25 NODE } \\
\hline \hline $\begin{array}{r}\text { Normalized } \\
\text { Routing } \\
\text { Load }\end{array}$ & 100 & 200 & 300 & 400 & 500 \\
\hline DSR & 0.029 & 0.018 & 0.015 & 0.011 & 0.011 \\
& & & & & \\
DSDV & 0.053 & 0.041 & 0.039 & 0.038 & 0.039 \\
AODV & 0.104 & 0.07 & 0.051 & 0.043 & 0.037 \\
\hline \hline
\end{tabular}

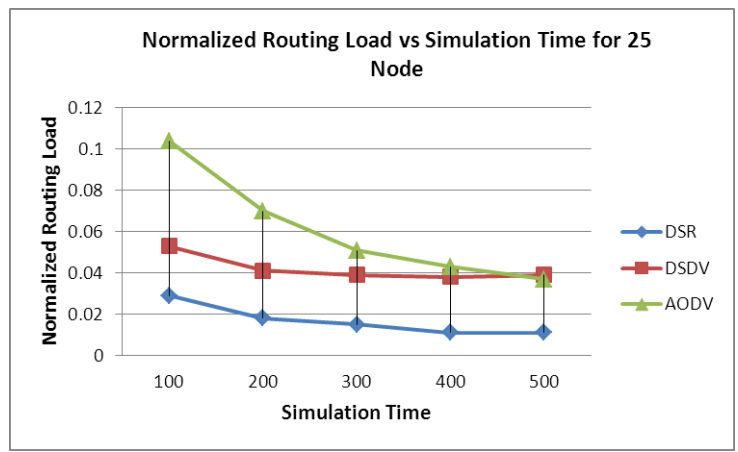

Fig. 15. Normalized routing load for 25 node.

TABLE XV: NORMALIZED ROUTING LOAD RESULTS FOR 50 NODE

\begin{tabular}{lccccc}
\hline \hline $\begin{array}{l}\text { Normalized } \\
\text { Routing } \\
\text { Load }\end{array}$ & 100 & 200 & 300 & 400 & 500 \\
\hline DSR & 0.182 & 0.118 & 0.1 & 0.087 & 0.079 \\
DSDV & 0.168 & 0.136 & 0.16 & 0.188 & 0.225 \\
AODV & 0.525 & 0.425 & 0.389 & 0.354 & 0.339 \\
\hline
\end{tabular}




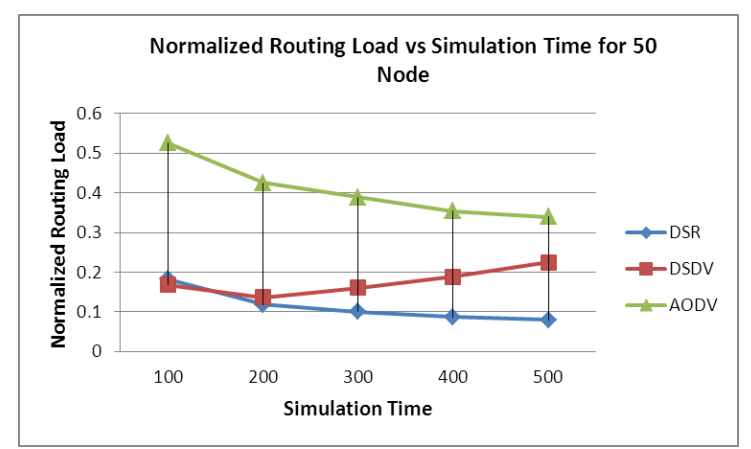

Fig. 16. Normalized routing load for 50 node.

TABLE XVI: NORMALIZED ROUTING LOAD RESULTS FOR 75 NODE

\begin{tabular}{lccccc}
\hline \hline $\begin{array}{l}\text { Normalized } \\
\text { Routing } \\
\text { Load }\end{array}$ & 100 & 200 & 300 & 400 & 500 \\
\hline DSR & 0.221 & 0.142 & 0.123 & 0.101 & 0.099 \\
DSDV & 0.228 & 0.194 & 0.24 & 0.471 & 0.709 \\
AODV & 1.112 & 0.964 & 0.862 & 0.77 & 0.73 \\
\hline \hline
\end{tabular}

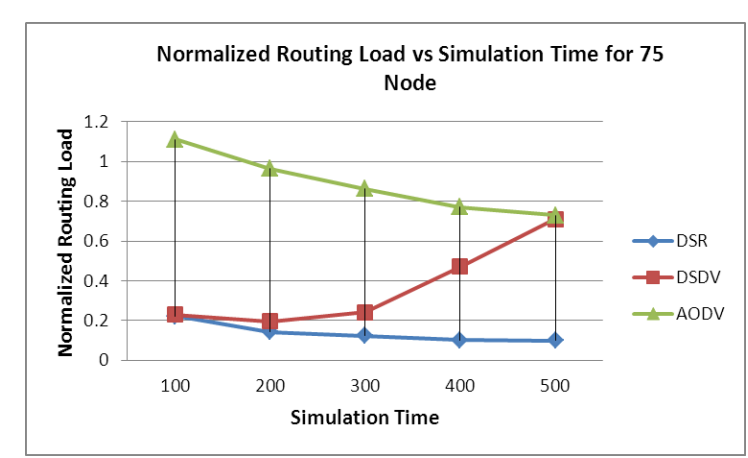

Fig. 17. Normalized routing load for 75 node.

In Normalized Load view, DSR typically uses larger routing packets because of source routing, and DSR data packets carry routing information in form of source routes and these could be counted as a part of routing load.

\section{CONCLUSION}

First, by comparing these protocols on the basis of various performance metrics we have reached to a conclusion that reactive topology based protocols are better than proactive topology based routing protocols.

Second, DSR is well suited for static and low-mobility networks. High mobility reduces its performance. AODV reduces the network wide broadcasts to the extent possible significant reduction in control overhead as compared to DSDV Potentially, very high overhead Data packets may be delivered to too many nodes who do not need to receive them. Potentially lower reliability of data delivery Flooding uses broadcasting -- hard to implement reliable broadcast delivery without significantly increasing overhead "Broadcasting in IEEE 802.11 MAC is unreliable".

Also the interplay between the routing and MAC layers could affect performance significantly. For example, even though DSR generated much fewer routing packets overall, it generated more unicast routing packets which were expensive in the 802.11 MAC layer we used. Thus DSR's apparent savings on routing load did not translate to an expected reduction on the real load on the network. This observation also emphasizes the critical need for studying interactions between protocol layers when designing wireless network protocols.

Finally, a new algorithm is needed to avoid the disadvantages of each as much as possible, and collect all advantage of each protocol to get much better performance.

Further, the description of the design structure and additional features of each implementation can assist users in deciding which implementation best fits their needs.

\section{REFERENCES}

[1] S. Taneja and A. Kush, "A survey of routing protocols in mobile ad hoc networks," vol. 1, no. 3, August 2010.

[2] G. Singh," MANET: Issues and behavior analysis of routing protocols," International Journal of Advanced Research in Computer Science and Software Engineering, vol. 2, April 2012.

[3] P. Manickam, T. Guru Baskar , M. Girija, D. Manimegalai, "Performance comparisons of routing protocols in mobile ad hoc networks," International Journal of Wireless \& Mobile Networks (IJWMN), vol. 3, no. 1, February 2011.

[4] A. Makkar, B. Bhushan, Shelja, and S. Taneja,"Behavioral study of MANET routing protocols," International Journal of Innovation, Management and Technology, vol. 2, no. 3, June 2011.

[5] S. Toumpis, Wireless ad-hoc networks, in: Vienna Sarnoff Symposium, Telecommunications Research Center, and April 2004.

[6] P. Rohal1, R. Dahiya, and P. Dahiya," Study and analysis of throughput, delay and packet delivery ratio in MANET for topology based routing protocols (AODV, DSR and DSDV)," International Journal for Advance Research in Engineering and Technology, vol. 1, March 2013.

[7] M. B. Subramanya, D. Shwetha, and T. J. Devaraju, "A performance study of proactive, reactive and hybrid routing protocols using qualnet simulator," International Journal of Computer Applications (0975 8887) vol. 28, no. 5, August 2011.

[8] L. Abusalah, A. Khokhar, and M. Guizani, "A survey of secure mobile ad hoc routing protocols," IEEE Communications Surveys \& Tutorials, vol. 10, no. 4, 2008.

[9] M. Keshtgary and V. Babaiyan, "Performance evaluation of reactive, proactive and hybrid routing protocols in MANET," IJCSE, vol. 4 no. 2, February 2012.

[10] A. Anzaar, H. Shahnawaz, C. Mukesh, S. C. Gupta, R. Gowri, and H. L. Mandoria, "Simulation study for performance comparison of routing protocols in mobile adhoc network," pp. 684-686, 2010.

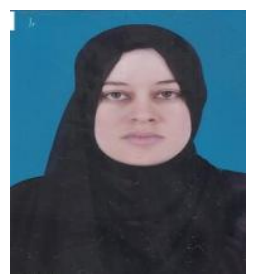

Suhaila A. Dabibbi was born on 13 January, 1985, in Alkhoms, Libya. She obtained the bachelor of computer science, Elmergib University, Libya in 2006

She worked as a teaching assistant from 2007 to 2008 in Elmergib University, Libya. Her research interest are research programming, coding, networks, information security, software quality and mobile networks. Now, she studies in Institute of Graduate Studies \& Research (IGSR), Alexandria University, Egypt.

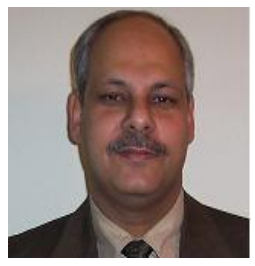

Shawkat K. Guirguis was born on 25th February, 1958, in Alexandria, Egypt. He obtained the B.Sc. and M.Sc. degrees in computer science $\&$ automatic control, Faculty of Engineering, Alexandria University, 1981 and 1984 respectively with Grade: "Distinction with the degree of honor". In 1988 he obtained a Ph.D. in electronics and communication, Cairo University, Co-Supervised by Imperial College of Science and Technology, University of London, U.K.

$\mathrm{He}$ is currently a professor of computer science and informatics, Department of Information Technology, Institute of Graduate Studies \& Research (IGSR), Alexandria University, Egypt. His current research interests include network and information security, data mining and cloud computing. 